\section{Simpósio de Educação Médica de Botucatu: a interdisciplinaridade e a avaliação no curso de Medicina}

\author{
$7^{\text {th }}$ Botucatu Medical Education Symposium: \\ interdisciplinarity and evaluation on Medical course
}

Em agosto de 2007, aconteceu a sétima edição do Simpósio de Educação Médica de Botucatu, organizado pelo Centro Acadêmico Pirajá da Silva (CAPS), da Faculdade de Medicina de Botucatu/Unesp. Ganhando tradição nesta faculdade a cada ano, o evento contou com cerca de duzentos participantes, entre docentes e estudantes de graduação em Medicina, para discussão da temática da interdisciplinaridade no currículo médico e da avaliação do processo de aprendizagem - tanto na esfera cognitiva quanto normativa.

O tema interdisciplinaridade surgiu da constatação da debilidade desse tema no currículo médico: propostas de integração disciplinar no curso têm falhado sistematicamente - tanto na área básica quanto na aplicação clínica durante o Internato. Além disso, não houve trabalhos inscritos na área durante o 5. ${ }^{\circ}$ Congresso Paulista de Educação Médica, realizado em 2006 na Faculdade de Medicina da Unesp, o que pode apontar para uma fragilidade em outras escolas médicas neste campo da formação.

O tema avaliação mereceu ser abordado no simpósio por sua relevância no cenário médico-acadêmico em 2007 - ano de participação da Medicina no Exame Nacional de Cursos, ENADE; terceira edição do exame do Conselho Regional de Medicina de São Paulo, CREMESP; e mudança nos processos seletivos para Residência Médica, com a inclusão de provas práticas.

No primeiro dia, a discussão foi centrada na questão da interdisciplinaridade no ensino médico. A professora Sylvia Helena Souza da Silva Batista, do Centro de Desenvolvimento do Ensino Superior em Saúde da Unifesp, apresentou referenciais teóricos que apontam para a necessidade de implementar a interdisciplinaridade como objetivo da formação, bem como instrumento para as transformações necessárias ao curso médico. Em seguida, as professoras Dora Maria Grassi-Kassisse e Maria Almerinda Vieira Fernandes Ribeiro, da Unicamp, apresentaram as modificações realizadas no curso médico da Faculdade de Ciências Médicas da Unicamp, o qual volta-se para um ensino com base em módulos integradores.

As apresentações provocaram as discussões da Mesa-Redonda moderada pela professora. Eliana Goldfarb Cyrino e pelo acadêmico Pedro Tadao Hamamoto Filho, ambos da FMB/ Unesp. Os temas foram bastante úteis para os presentes ao Simpósio, até porque a faculdade passa por um momento de discussão e repactuação de seu Projeto Político-Pedagógico. Assim, foi lembrada a importância dos cenários de ensino e prática como despertadores da necessidade de integração disciplinar, na medida em que a assistência à saúde cria $a$ demanda de abordagem multiprofissional para o usuário do sistema. Também foi amplamente debatido o erro a que se incorre nas tentativas de integração disciplinar quando esta é reduzida a uma simples sincronização de conteúdos. Por fim, abordou-se a necessidade de integrar 
conteúdos das ciências ditas básicas com os de aplicação clínica, haja vista a importância de que o estudante compreenda a relevância e aplicabilidade dos temas básicos e os incorpore em sua prática clínica.

No segundo dia, foram trabalhados os aspectos da avaliação do médico recém-formado ou em formação. $O$ professor Luiz Ernesto de Almeida Troncon, da USP de Ribeirão Preto, descreveu como tem sido feita a aplicação de provas práticas nos processos seletivos para a Residência Médica. Ele destacou que o ganho principal obtido nessa aplicação não é a maior discriminação de aptos ao ingresso nos programas de Residência Médica mas, sim, a transformação que impõe aos alunos durante o Internato, impulsionando-os para maior interesse em atividades práticas e realização de procedimentos reduzindo, dessa forma, a importância outrora dada ao estudo essencialmente teórico.

O professor Troncon foi sucedido pela professora Márcia Regina Ferreira Brito Dias, da Unicamp, consultora do Exame Nacional de Desempenho dos Estudantes (ENADE/INEP/MEC). Ela apresentou o contexto em que se deu a modificação do sistema de avaliação de cursos no país, destacando dados do desempenho dos cursos de Medicina, em especial da FMB/Unesp, à luz das análises que o Instituto Nacional de Estudos e Pesquisas Educacionais (INEP/ MEC) tem desenvolvido frente aos resultados obtidos.

O professor Joélcio Francisco Abbade, da FMB/Unesp, apresentou, em seguida, o Teste Interinstitucional do Progresso - iniciativa da parceria entre escolas médicas de São Paulo, Paraná e Santa Catarina. O teste é aplicado, conjuntamente, a todos os alunos de graduação dessas escolas e destinado a alunos de primeiro a sexto ano. Dividido em seis áreas (Clínica Médica, Cirurgia, Saúde Pública, Ginecologia e Obstetrícia e Pediatria, além de Ética, incorporada em algumas questões), tem grande utilidade em apontar o acúmulo de conteúdos ao longo da graduação, diagnosticando a situação da escola em relação a outras sem, no entanto, fazer um ranking de desempenhos.

Na última apresentação do dia, o professor. Reinaldo Ayer de Oliveira, da FMUSP, e conselheiro do Conselho Regional de Medicina de São Paulo (Cremesp), mostrou os resultados preliminares da Avaliação dos Egressos Recém-Formados do Estado de São Paulo, proposta empreendida pelo Cremesp que tem gerado polêmica entre as escolas médicas. Embora apresentada como instrumento de resposta à abertura indiscriminada de escolas médicas e servir como mais uma avaliação das escolas, a iniciativa é bastante recriminada pelos estudantes, na figura da DENEM (Direção Executiva Nacional dos Estudantes de Medicina), vista com parcimônia por algumas faculdades (a Congregação da FMB/Unesp já emitiu documento contrário ao exame) e refutada pela ABEM, Associação Brasileira de Educação Médica, que critica a competência do Conselho em cumprir os objetivos a que se propõe.

Ao final, a Mesa-Redonda moderada pela professora Lenice do Rosário de Souza (FMB/Unesp) e pelos acadêmicos Priscila Beatriz de Souza Medeiros (FMB/Unesp) e Ciro Matsui Jr. (FMUSP) debateu as questões apontadas.

O VII Simpósio de Educação Médica de Botucatu pôde cumprir seu objetivo de capacitação e sensibilização da comunidade acadêmica para temas clássicos do ensino médico - que se mantêm atuais e pertinentes, haja vista a constante busca das escolas médicas pelo aperfeiçoamento da formação profissional em saúde e pelo cumprimento das Diretrizes Curriculares Nacionais, no sentido de formar médicos atentos às necessidades sociais, capazes de promover assistência, prevenção e promoção à saúde.

A presença discente no evento correspondeu às expectativas - foi grande, como nas últimas edições, apesar do caráter técnico de algumas discussões. Surpreendeu-nos uma grande participação docente, inclusive de professores de outras escolas.

O simpósio tem apresentado uma característica de ganhos processuais à capacitação discente no âmbito da educação médica. Conquanto seja difícil vislumbrar o impacto imediato no comportamento dos alunos em sala de aula, temos a convicção de que este processo de capacitação tem contribuído para sedimentar opiniões, provocar questionamentos e induzir à reflexão, ao menos, dos membros do Centro Acadêmico - estes, em última instância, pelas discussões, pelo trabalho em equipe e contato formal com professores de outras instituições, fortalecem um acúmulo de vivências e aporte teórico necessários para disseminar posturas que caracterizam a participação estudantil frente aos desafios de avanço da escola médica. 
Para que o processo de discussão em educação médica seja legítimo, é necessário que grande parte da comunidade acadêmica esteja participante e envolvida, tanto docentes quanto funcionários e alunos. Os alunos da Faculdade de Medicina de Botucatu sempre exerceram um papel de liderança nas discussões, na viabilidade da implementação das propostas e no acompanhamento do movimento de mudança. Sendo uma instituição de ensino tradicional, as resistências dentro do ambiente acadêmico sempre foram grandes e, em alguns momentos, coube aos alunos impulsionarem as discussões na área da formação médica. O VII Simpósio de Educação Médica foi, portanto, mais uma etapa do contínuo processo de amadurecimento das discussões de ensino na faculdade, em especial neste momento de reflexão sobre seu Projeto Político-Pedagógico.

Pedro Tadao Hamamoto Filho' Licério Miguel ${ }^{1}$ Ludmila Almeida Silva ${ }^{1}$ Ana Cristina Paschoal e Caldas ${ }^{1}$ Giovana Tuccille Comes ${ }^{1}$ Vinicius Cunha Venditti Thalita Azevedo Fracalossi ${ }^{1}$ Vanessa dos Santos Silva ${ }^{2}$ 